\title{
Designing and Developing a Romanised Mandarin Web-based Instruction for Non-native Learners in Malaysia
}

\author{
${ }^{*}$ Lim Soo Giap, Ong Sheau Fen \\ Academy of Language Studies Universiti Teknologi MARA (UiTM), Malaysia \\ *limsoogiap266@ppinang.uitm.edu.my
}

\begin{abstract}
Hanyu Pinyin (Romanised Mandarin) is taught as part of the teaching Mandarin as a third language in UiTM. The time allocated to teach the sound system of Hanyu Pinyin is insufficient for learners. Hence, it is suggested a web-based instruction incorporate into the curriculum as a self-learning material for learners to enable them to manage their learning process in the absence of instructor. The objective of this paper is to describe the process of designing and developing a Hanyu Pinyin WBI to teach non-native learners (Malay Mandarin learners) in learning Mandarin at a Malaysian university (UiTM). The Hanyu Pinyin WBI is tailored to tackle the weaknesses and to meet the specific needs of Malay learners. Hanyu Pinyin WBI is designed on the basis of Instructional System Design (ISD) methodology. This approach involves four phases: (1) analysis and design, (2) development, (3) implementation, and (4) evaluation of the instruction.
\end{abstract}

Keywords: Web-based instruction; instructional system design; Romanised Mandarin

\section{Introduction}

One of the ways to deliver a language course on learners' demand using any computer connected to the Internet at anywhere and anytime is by developing a Web-based instruction (WBI). Besides, it can be more effective if WBI incorporates multimedia components. 'A picture tells a thousand words', thus, a Mandarin WBI that includes multimedia elements will increase the effectiveness in learning Mandarin. Web-based instruction, which is also called as Web-based training, is defined as an "individualised instruction that is delivered over public or private computer networks and displayed by a Web browser". WBT is not a downloaded Computer Based Training but an on-demand training stored in a server and accessed across a network. Web-based training can be updated very rapidly and its accessibility as a training tool is fully controlled by the training provider (Clark, 1996).

Hanyu Pinyin (Romanised Mandarin) is taught as part of the teaching Mandarin as a third language in UiTM (University of Technology of MARA). The time allocated to teach the sound system of Hanyu Pinyin is insufficient for learners. Many learners who are exposed to Mandarin for the first time fail to satisfactorily comprehend the intricacies of its sound system. Hence, it is necessary to devise a self-learning material for learners to enable them to manage their learning process in the absence of instructor. The Hanyu Pinyin webbased instruction (WBI) is specially designed to overcome the weaknesses in learning Mandarin pronunciation based on the specific needs of Malay learners. It is designed on the basis of instructional system design (ISD) methodology. This approach involves four phases: (1) analysis and design, (2) development, (3) implementation, and (4) evaluation of the instruction.

In order to create a conducive environment for learning Hanyu Pinyin, one of the suggested alternatives is to incorporate the web-based instruction into the curriculum. Based on the objective of the study, the question is formulated as: How to design and develop a Hanyu Pinyin WBI to teach non-native learners in learning Mandarin at a Malaysian university?

\section{Literature Review}

Among the well-designed and established Hanyu Pinyin WBI according to Shao (Shao, 2005), are the Chinese Pronunciation Guide of Harvard University and the Pinyin Pronunciation for Mandarin of Oxford University.

Chinese Pronunciation Guide of Harvard University: Harvard University's "Hanyu Pinyin Lianxi Zhinan" (A guide to Pinyin pronunciation practice): The website is structured in a way that progresses from lower to 
higher level skills incorporating explanations on the consonants and vowels of Mandarin and their combinations. It also outlines some of the difficulties encountered by English speakers in learning Mandarin. Besides exercises in the pronunciation of individual sounds and the four tones in Mandarin, the website also includes practices in tonal combinations. The former is helpful to learners in learning individual words so that they can grasp the syllable structure and principles of Mandarin pronunciation from the very beginning whereas the later facilitates the learning of phrases. Since most of the words in Mandarin are disyllabic, this website has rightly incorporated pronunciation practices in two-syllable words. It is true that if one is familiar with the pronunciation of two-syllable words then the study of tonal combinations later would be much easier. Other than two-syllable words, learners must also pay extra attention to "tonal variation" especially two-syllable words with two consecutive third tone which is amply covered in this website. However, the site does not provide immediate feedback to learners based on their performance. Thus if learners are not discerning enough it would be difficult for them to distinguish the difference between certain sounds. For example the retroflex sounds $\mathrm{zh}, \mathrm{ch}$, sh and the sibilants $\mathrm{z}, \mathrm{c}$ and $\mathrm{s}$. One drawback of the site is that, although it has outlined all the syllable structures in Mandarin, it provides no mechanism for learners to listen to their pronunciations (Shao, 2005).

Pinyin Pronunciation for Mandarin of Oxford University: Basically the Oxford University's Pinyin Pronunciation for Mandarin resembles the Harvard's zhinan. However, the site differs from Harvard's in that it also makes use of pictures to facilitate the learning process. It is an accepted fact that one learns from the concrete to the abstract and the inclusion of pictures in this site makes the task of memorizing the sounds of Mandarin less daunting. One interesting feature of the pictures used is that they are selected based on the cultural background of learners. Take for example the consonant $t$, it is described that it sounds like the English word "tea"; the picture used is a coffee cup containing peach-red liquid. One can see the difference in the definition of "tea" from the Chinese and Western perspectives. For the Chinese, the tea cup does not contain any handle and the colour of tea is usually light brownish, never peach-red. However, what is shown in the picture is quite normal for learners in England. Certainly, it is natural to base the teaching of Mandarin on the foundation of the learners' culture. Elements of Chinese culture can be incorporated gradually at a later stage. Another useful feature of the site is that learners can listen to the articulation of every syllable outlined.

The contents of the two websites mentioned above are not designed and arranged in accordance with any existing teaching materials and as a result they can be modified easily. Similarly, they can be accessed by not only students from the two universities but the public as well. Since the two sites are not based on existing teaching materials, they focus mostly on vowels, consonants, word-level and phrase-level tones. For learners, they benefit from these two sites more on the learning of word-level rather than sentence-level tones. In terms of feedback for learners, there is no such provision on both sites (Shao, 2005).

Hanyu Pinyin WBI of the Chinese University of Hong Kong: In a survey, Xu (2005) selected twelve popular Hanyu Pinyin WBIs and graded them according to ten criteria. The result shows that the Hanyu Pinyin WBI of the Chinese University of Hong Kong is far more superior to others. The Hanyu Pinyin WBI of the Chinese University of Hong Kong is exceptionally interesting and challenging for learning Hanyu Pinyin as its content has included storytelling and RPG (Role-Play Game). Learners are required to choose one of the two options from the main page to start their lesson. They can start with the Hanyu Pinyin Pronunciation rules or the syllable tables (a lesson for learners to practise the consonants, vowels and syllable construction by manipulating the various consonants, vowels and tones). The materials are presented in such a way that learners are required to assume an active role in accomplishing the task given. However, the instruction language is in Mandarin, and therefore not suitable for those who are not proficient in the language.

\section{Methodology}

In order to answer the research question, below is the description of the process to design and develop Hanyu Pinyin WBI based on the instructional system design (ISD) methodology. 
Analysis and design phases: In the analysis phase, the learners' background, the instructional materials, and the delivery modes were carefully examined. This analysis provides inputs to the design of instructions such as refining the learning objectives, specifying the training media and lesson design.

Learner analysis is essential to ensure that the design of online materials is customized to the learners. The intended learners of Hanyu Pinyin Instruction are mainly targeted to fulltime students who have no prior knowledge of Mandarin. Thus, prior to this, a survey was done to identify learners' Hanyu Pinyin learning requirements by identifying the difficulties faced by the learners when learning Hanyu Pinyin and its pronunciation. Two methods were used to collect the data: at first from the facilitator's own teaching experience and secondly, by referring to previous studies of pronunciation errors from UiTM Mandarin lecturers. This piece of data is required not only to determine the learning outcome that will best meet the learners' needs but also to develop an outline of the content, course objective, learning strategies, and assessment items that will realise those outcomes.

Lee, Lau \& Mok (2004) had done an analysis on the pronunciation errors of initials and tone in speaking Mandarin among UiTM learners. It shows that learners make the most common mistakes in pronouncing the plosive initials (33.7\%), followed by the affricate initials (25.0\%), and fricative initials $(21.4 \%)$. In terms of plosive initials, most of the learners make mistake in pronouncing $p$ initial (83\%), $t$ initial (85.8\%), and $k$ initial (54.5\%). For affricate initials, a good number of mistakes are found in pronouncing $q$ initials (44.9\%), ch initial (82.7\%), and $c$ initial (44.0\%). In fricative initials, majority of the learners make mistakes in pronouncing the $s h$ initial (48.3\%). From the statistic, it depicts that most learners were facing difficulties in pronouncing the initials with aspirated sounds.

For tone pronunciation error, the research shows that there are mainly four categories of errors. The errors are incorrect pronouncing the first tone, second tone, third tone, and fourth tone. The sequence of pronunciation error from highest to lowest are the second tone (59.5\%), the fourth tone (52.8\%), the third tone $(36.7 \%)$, and the first tone $(27.5 \%)$. In other words, the average mistakes that learners make in pronouncing is the second tone, followed by the fourth tone, subsequently the third tone, and lastly the first tone ( Lee, et al. 2004). The data obtained from the research above has provided a fine input to the outline of the content, course objective, learning strategies, and assessment items of Hanyu Pinyin WBI. In addition, it has provided a comprehensible guideline to facilitator for producing pertinent lessons.

\section{Results}

It is also imperative that the feasibility and implications of various delivery modes are well investigated as the technology and media to be used for presenting the instruction has a broad range of implications for the design, development, and implementation of the instructions. The facilitator has two alternatives to deliver the instructions: using the CD-ROM and the Internet. Thus, in order to have a clearer view of the implications, the facilitator has listed out the functions, strengths, and limitations of the potential delivery modes to ease the work of analysis as shown in Table 1.

Table 1: The Function, Strengths and Limitation of Web-Based and CD-Rom Delivery Mode

\begin{tabular}{ll}
\hline WBI & CD-ROM \\
\hline $\begin{array}{l}\text { Flexible in updating and adding course } \\
\text { content. }\end{array}$ & $\begin{array}{l}\text { Updating of course content needs to produce a large } \\
\text { amount of new CDs. }\end{array}$ \\
$\begin{array}{l}\text { Slow loading time (depends on server) } \\
\text { Limited access (no Internet service in }\end{array}$ & $\begin{array}{l}\text { Unick loading time } \\
\text { computer) access (learner can access it with any }\end{array}$ \\
$\begin{array}{l}\text { certain area) } \\
\text { Subscribing the Internet is more expensive }\end{array}$ & Buying a CD is cheaper
\end{tabular}


From the functions, strengths, and limitation listed above, it is apparent that these two methods complement each other. By adopting both methods it can assure that the Hanyu Pinyin instruction can be reached by all potential users.

The following step is to choose the web instruction development tools (software). The chosen web instruction development tools were Adobe Dream Weaver CS4, Adobe Flash CS4, Sound Forge 4.5, Microsoft Internet Explorer 6.x or later, HTML, XML and Hotpotato. Adobe Dream Weaver CS4 is a web authoring tool while the main function of Adobe Flash CS4 is to create graphics and flash movies. The strengths of both tools are: (1) widely accepted by the market; (2) possess multiple functions; and (3) attractive design outcomes. Sound Forge 4.5 is a professional sound editing tool which is used for digital sound recording and audio editing. The web browser used in the study was Microsoft Internet Explorer 6.x or later because it is widely used by global users. The main function of HTML and XML are scripting and they are widely used by instruction developer. Hotpotato is also used to create exercise and quizzes. Table 2 shows the development tools used and their functions in the instruction development process.

Table 2: Software Requirements and their Strengths of Hanyu Pinyin Instructions

\begin{tabular}{|c|c|c|}
\hline $\begin{array}{c}\text { Instruction } \\
\text { development tools }\end{array}$ & Function & Strenghts \\
\hline $\begin{array}{l}\text { Adobe } \\
\text { DreamWeaverCS4 }\end{array}$ & Web authoring tool & $\begin{array}{l}\text {-widely accepted by the market } \\
\text {-possess multiple functions } \\
\text {-the design outcomes are attractive }\end{array}$ \\
\hline AdobeFlashCS4 & $\begin{array}{l}\text { Creating graphics and } \\
\text { Flash movies }\end{array}$ & $\begin{array}{l}\text {-widely accepted by the market } \\
\text {-process multiple functions } \\
\text {-the design outcomes are attractive }\end{array}$ \\
\hline Sound Forge 4.5 & $\begin{array}{l}\text { Digital sound recording } \\
\text { and audio editing }\end{array}$ & Professional sound editing tool \\
\hline $\begin{array}{l}\text { Microsoft Internet } \\
\text { Explorer 6.x or later }\end{array}$ & Web browser & Widely used by the users \\
\hline $\begin{array}{l}\text { HTML } \\
\text { XML }\end{array}$ & $\begin{array}{l}\text { Scripting } \\
\text { Scripting }\end{array}$ & $\begin{array}{l}\text { Widely used by instruction developer } \\
\text { Widely used by instruction developer }\end{array}$ \\
\hline Hotpotato & $\begin{array}{l}\text { Creating exercise and } \\
\text { quizzes }\end{array}$ & User friendly \\
\hline
\end{tabular}

To set up a comfortable WBI project creation environment, the following conditions must be met:

a) $\quad$ CPU - Core2duo Microprocessor or equivalent

b) $\quad$ RAM - 2 GB (Minimum), 4 GB (recommended)

c) Hard disc storage $-100 \mathrm{~GB}$ and above

As a supplementary learning and teaching aids, the main purpose of the instruction is to reinforce and drill the learners with what they have learnt in the class. To fulfil their needs, the Hanyu Pinyin Instruction had adopted 11 modules that led the learners through a series of step-by-step tutorials followed by additional exercises and quizzes for drilling and practicing. To design the instruction, the objective and the learning steps were identified. Test items such as quizzes were developed while the content sequencing and structuring were also clearly laid out.

Development phase: Implementation of the designing ideas into the development phase involves two processes that start from flow charting followed by storyboarding and end with development of the instruction. 
Figure 1 : The logical representation of Hanyu Pinyin Instruction starting from the main menu to the various modules

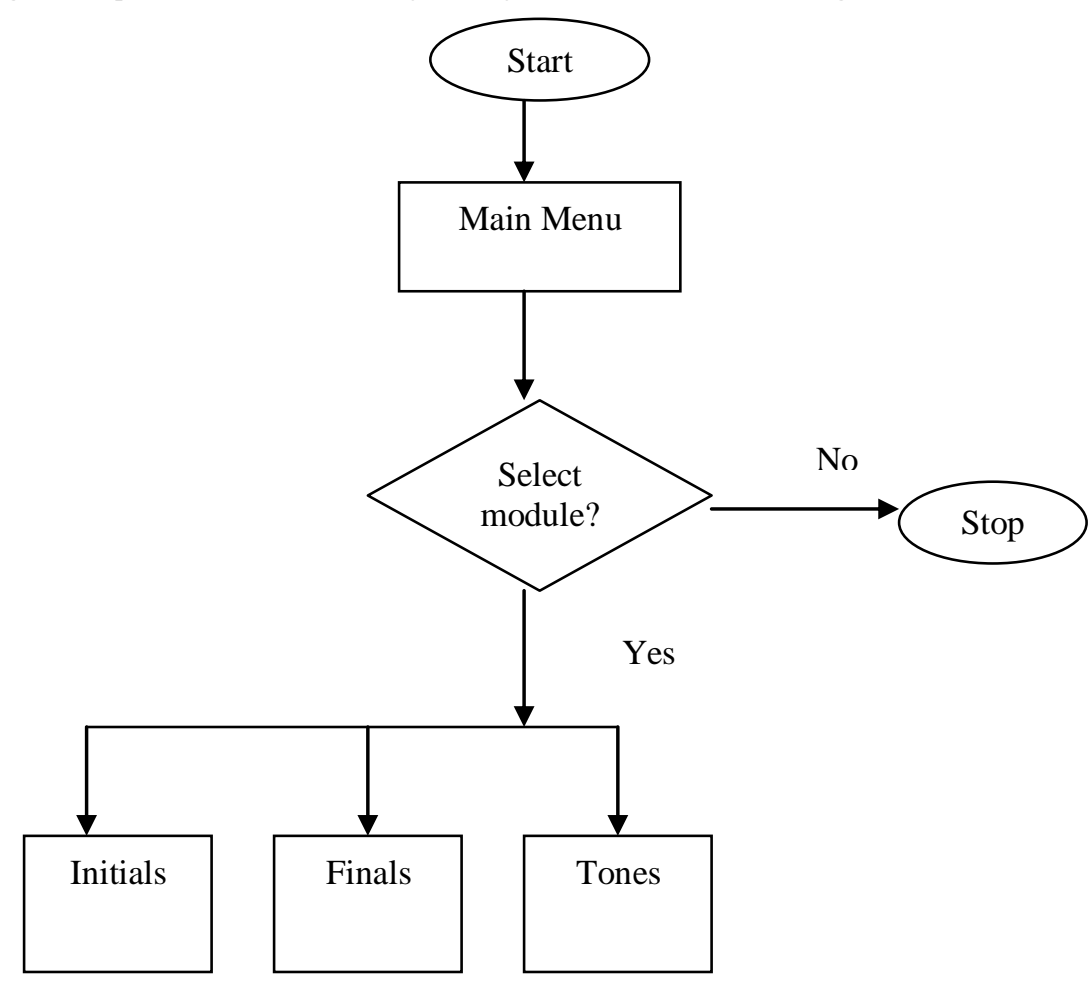

A flowchart is a tool that helps to plan the flow of information for developing an instruction. The flow chart created depends on the learning strategies. The ellipse (start and stop) is used to designate where the course begins and ends. The connector symbol (the blocky arrow) is used to link sections of the flow chart. The diamond symbol is used whenever the learner makes a decision. The rectangle symbol is used to show information presentation. Fig. 1 depicts an extract of a Hanyu Pinyin Instruction flowchart that reveals what takes place when a learner makes a decision and what kind of branching option is possible in the instruction.

Storyboarding is a pencil and paper technique for designing and testing user interface (Lohr, L. 2000). Using pencil is quick and easy; however, it is also convenient to use drawing tools (MS Paint, Adobe Illustrator, CorelDraw etc) to layout the storyboard if the facilitator is proficient in using them. The storyboard takes each section of the flow chart and "shows" what is going on in the lesson. Aspects such as project name, designer's name, page title, page number, the interface screen design, actions and multimedia elements are addressed in the storyboard. This process is crucial in gathering the contents of instruction such as assets that are needed, assets that have to be created, and assets that have been accumulated for the next stage of the development process. The details of the Hanyu Pinyin Instruction's storyboard are shown in Fig. 2.

Figure 2 : A blank document of storyboard

\begin{tabular}{|l|l|}
\hline Project name: & Designer: \\
\hline Page title: & Page number: \\
\hline Interface screen design: & Actions: \\
& \\
& \\
\cline { 2 - 2 } & Multimedia element descriptions: \\
\hline
\end{tabular}


Figure 3: Hanyu Pinyu Instruction's Storyboard

\begin{tabular}{|c|c|c|c|c|}
\hline \multicolumn{3}{|c|}{$\begin{array}{l}\text { PROJECT NAME: To invent a state of art technology on web } \\
\text { based Hanyu Pinyin instruction to facilitate self learning } \\
\text { Mandarin for non native Mandarin learners. }\end{array}$} & \multicolumn{2}{|c|}{ Designer: Lim Soo Giap and Ong Sheau Fen } \\
\hline \multicolumn{3}{|l|}{ Page Title: Laman Utama } & \multicolumn{2}{|c|}{ Page Number: 1} \\
\hline \multicolumn{3}{|l|}{ Interface/Screen design: } & \multicolumn{2}{|l|}{ Action: } \\
\hline Logo & \multicolumn{2}{|c|}{ Menu } & & \\
\hline \multicolumn{3}{|c|}{ Banner } & masuk: & \\
\hline $\begin{array}{ll} & \text { Ahli Log masuk } \\
- & \text { ID Ahli } \\
- & \text { Kata Laluan }\end{array}$ & \multirow{3}{*}{\multicolumn{2}{|c|}{$\begin{array}{c}\text { Selamat Datang } \\
\text { Pengenalan } \\
\text { Objektif }\end{array}$}} & mendaftar: & $\begin{array}{l}\text { Click and go to input page for } \\
\text { registration. }\end{array}$ \\
\hline Macuk & & & Seterusnya: & Click and go to "Peraturan" \\
\hline & & & & page. \\
\hline $\begin{array}{c}\text { Daftar } \\
\text { sebagai ahli }\end{array}$ & \multirow{4}{*}{$\begin{array}{l}\text { Langkah- } \\
\text { langkah } \\
\text { mempelajari } \\
\text { sistem } \\
\text { sebutan } \\
\text { bahasa } \\
\text { Mandarin }\end{array}$} & \multirow[t]{2}{*}{ Seterusnya } & & \\
\hline \multirow{3}{*}{ Jumlah Pelawat } & & & & \\
\hline & & & & \\
\hline & & & & \\
\hline \multicolumn{3}{|c|}{ Guru Hanyu Pinyin @ 2010} & & \\
\hline & & & & \\
\hline
\end{tabular}

Fig. 3 shows one of the Hanyu Pinyin instruction's storyboard designed by the authors. The project title is 'To invent a state of art technology on web based Hanyu Pinyin instruction to facilitate self-learning Mandarin for non native Mandarin learners'. The designers' names are 'Ong Sheau' Fen and 'Lim Soo Giap'. The page title is 'Laman Utama' and the page number is ' 1 '. The interface screen design includes logo, menu, banner, member log in, member registration, and next page. Using mouse to click on the 'masuk' (log in) button will access to main menu page; 'mendaftar' (registration) will go to input page while 'seterusnya' (next page) will go to 'peraturan' (rules) page. Based on the storyboard, the next step is to develop the instruction. It involves the use of selected media and development tools decided in the analysis phase. Once the instruction is completely developed, it is uploaded to the Internet.

Implementation phase: The implementation phase refers to the actual delivery of the instruction. It is laboratory-based. A group of 20 Hotel Management students who were required to take Mandarin as a skill paper were brought to the laboratory to attend a self-learning session by accessing the instruction from the Internet. A short briefing was conducted covering course objectives, course descriptions, and instruction utilisation methods were presented to the students before they use the instruction. 
Evaluation phase: The effectiveness of the instruction was evaluated by 2 instruments: a test of Hanyu Pinyin and questionnaires to investigate the user friendliness of the instructions with the purpose of improving the instruction. Data collected from the first instruments were analysed using the SPSS 12.5.20 BMD110 Hotel Management Diploma students in UiTM Penang campus were selected to attend a 4-hour selflearning session by using Hanyu Pinyin instruction at the language computer laboratory, another 20 students acted as the control group who were taught using the conventional teaching approach with no exposure to Hanyu Pinyin instruction. In addition, the Hanyu Pinyin test results and the scores from the "WBI Hanyu Pinyin instruction user friendliness questionnaire" were used to collect data for the first and second research questions.

A comparison of means scores on Hanyu Pinyin test results had also been carried out to get data for the research question. To validate the hypotheses, Independent Pair Samples T-test was conducted on students' Hanyu Pinyin test scores. An open-ended questionnaire was carried out to investigate the students' view about improving the Hanyu Pinyin instruction before it was used as a major teaching instruction in teaching and learning of Hanyu Pinyin.

\section{Conclusion}

Most of the Web-based Instruction (WBI) for Chinese focuses on grammar and vocabulary. Comparatively, the numbers of WBI on Pinyin pronunciation and Romanization are relatively small. Some WBI are resourceful, however, they address to the particular needs of their targeted learning entities thus it is impossible to adopt the entire set of these WBI to facilitate the Malay Hanyu Pinyin learners. Besides choosing the sections that are relevant from these instructions to enhance teaching or learning, lecturer should take full advantage of the currently available web authoring tools to create Hanyu Pinyin WBI specifically tailored to non-native learners. The lecturer needs not possess any programming skills to develop Hanyu Pinyin WBI as presently there are plenty of user-friendly web authoring tools available and even amateur can put up functional web sites with these tools. Therefore, lecturer should take the opportunity to create their own Hanyu Pinyin WBI tailored to the specific needs of their learners. If the self-created WBI is interesting and innovative, learners will get the most benefits from it which will result in more effective learning of Hanyu Pinyin. It is recommended that the future research could target on the areas described for web based course module development. Besides that, replication of the study can be carried out for others languages.

\section{References}

Clark, G. (1996). Glossary of CBT/WBT Terms. Retrieved January 07, 2010 from http://www.clark.net/pub/nractive/alt5.htm.

Lee, A. C., Lau, S. K. \& Mok, S. S. (2004). The error of the initial phonemes and tones in Mandarin speech: A case study for diploma students, UiTM Shah Alam / Lee Ai Chat, Lau Suk Khin, Mok Soon Sim. Technical Report. Institute of Research, Development and Commercialization, University Teknologi MARA.

Lohr, L. (2000). Graphic Design [Online]. Colorado: University of Northern Colorado. Retrieved January 7, 2007 from http://www.alpha.nsula.edu/-gilianI08id.htm.

Shao, B. Y. (2005). A brief introduction of Online Hanyu Pinyin Web Sites] [Online].Taiwan: International Conference on Internet Chinese Education. Retrieved December 20, 2005 from http://edu.ocac.gov.tw/discuss/academy/netedu04/ICICE2005/html/paper2/C12.pdf.

Xu, Z. J. (2005). A Review and Evaluation of Online Hanyu Pinyin Web Sites. Taiwan: International Conference on Internet Chinese Education. Retrieved December 20, 2001 from http://edu.ocac.gov.tw/discuss/academy/netedu04/ICICE2005/html/paper2/C08.pdf. 